\title{
Éditorial
}

\section{Les Humanités menacées}

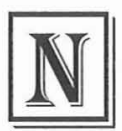

ous vivons une époque d'incertitudes. Le vingt et unième siècle s'est déjà annoncé violent. La peur paralyse nos jours et atrophie nos démocraties. Pour se protéger contre la terreur, les libertés les plus fondamentales sont restreintes ou sacrifiées. La tension publique et le désarroi social se mesurent quotidiennement en couleurs alarmantes. Nous sommes assiégés par des ennemis introuvables, peut-être inexistants, peutêtre parfois fabriqués par nos imaginations apeurées. La peur est-elle exploitée pour gouverner et faire taire l'opposition. Critiquer, manifester, n'est plus patriotique. La peur, d'ailleurs, une arme du gouverneur, devient contagieuse. Dans son Becket, Jean Anouilh fait dire avec sarcasme : "Il faut que les peuples aient peur. À la minute où ils cessent d'avoir peur, ils n'ont qu'une idée, c'est de faire peur à leur tour. »

André Malraux, jetant un coup d'œil prophétique vers l'avenir, dit d'une voix de Cassandre que le vingt-et-unième siècle sera religieux ou il ne sera pas. Je crois que ce mécréant célèbre ne fait pas d'acte de contrition, ni préconise-t-il un ordre social religieux, ou une vision existentielle qui comporte une dimension métaphysique. Ce qu'il exprime, plutôt, c'est la nécessité de nous éloigner des préoccupations matérialistes sociales et intellectuelles et donc d'affirmer de nouveau des valeurs humanistes, y compris des valeurs spirituelles ou intemporelles. Le début de ce siècle ne fait pas de bon augure. Serions-nous donc en voie de disparition, d'autodestruction? La menace apocalyptique malrucienne, "ou il ne sera pas ", nous revient en écho tonitruant.

Quelle serait notre attitude, face à ce présent instable et à un futur menaçant? Il me semble d'autant plus urgent de témoigner en faveur des activités créatrices. Il est temps de défendre à haute voix ce qui est du domaine de l'esprit contre tout matérialisme opprimant et tout raisonnement qui sonne faux. Rappelons la leçon du sage Aristote dans son Ethique de Nicomaque: "Quant aux vertus nous les acquérons d'abord par l'exercice, comme il arrive également dans les arts et les métiers. Ce que nous devons exécuter après une étude préalable, nous l'apprenons par la pratique. [...] De même, c'est à force de pratiquer la justice, la tempérance et le courage que nous devenons justes, tempérants et courageux. » Encourageons toujours donc les études humanistes, la poésie, les beauxarts, la défense de la paix et de la justice, toutes ces activités et valeurs 
inquantifiables, peu rentables, et si souvent jugées inutiles dans les antichambres du pouvoir. Maintenant plus que jamais, se justifie amplement ce que nous faisons modestement, chacun dans son petit coin du monde, en promouvant les arts et en reconnaissant la valeur inestimable des produits de notre esprit créateur.

Concluons avec une phrase sobre de William Faulkner, tirée de son roman Le Bruit et la fureur: "Les batailles ne se gagnent jamais. On ne les livre même pas. Le champ de bataille ne fait que révéler à l'homme sa folie et son désespoir, et la victoire n'est jamais que l'illusion des philosophes et des sots. "

Sergio Villani

Université York 